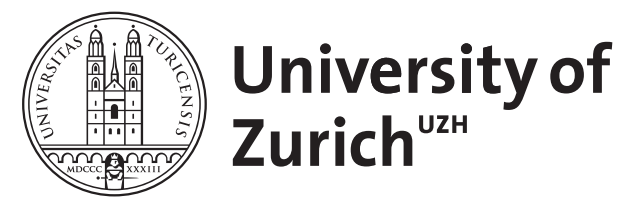

\title{
Protein epitope mimetics as anti-infectives
}

Robinson, J A

\begin{abstract}
There is growing interest in the design of synthetic molecules that mimic the structures and functions of epitopes found on the surface of peptides and proteins. Epitope mimetics can provide valuable tools to probe complex biological processes, as well as interesting leads for drug and vaccine discovery. One application of epitope mimetics is reviewed here, focusing on mimetics of the cationic antimicrobial peptides that form part of the innate immune response to microbial and viral infection in many organisms. Mimetics of these naturally occurring peptides and proteins may be useful to explore mechanisms of antimicrobial and immunomodulatory action, and as a potential source of new antibiotics to address one of the most pressing current threats to human health.
\end{abstract}

DOI: https://doi.org/10.1016/j.cbpa.2011.02.015

Posted at the Zurich Open Repository and Archive, University of Zurich

ZORA URL: https://doi.org/10.5167/uzh-54040

Journal Article

Accepted Version

Originally published at:

Robinson, J A (2011). Protein epitope mimetics as anti-infectives. Current Opinion in Chemical Biology, 15(3):379-386.

DOI: https://doi.org/10.1016/j.cbpa.2011.02.015 
Protein Epitope Mimetics As Anti-Infectives

John A. Robinson

Chemistry Department, University of Zurich, Winterthurerstrasse 190, 8057 Zurich Switzerland.

Tel: $++41-44635-4242$

E-mail: robinson@oci.uzh.ch 


\begin{abstract}
:
There is growing interest in the design of synthetic molecules that mimic the structures and functions of epitopes found on the surface of peptides and proteins. Epitope mimetics can provide valuable tools to probe complex biological processes, as well as interesting leads for drug and vaccine discovery. One application of epitope mimetics is reviewed here, focusing on mimetics of the cationic antimicrobial peptides that form part of the innate immune response to microbial and viral infection in many organisms. Mimetics of these naturally occurring peptides and proteins may be useful to explore mechanisms of antimicrobial and immunomodulatory action, and as a potential source of new antibiotics to address one of the most pressing current threats to human health.
\end{abstract}




\section{Introduction}

A "protein epitope mimetic" is a conformationally constrained synthetic molecule that mimics the three-dimensional (3D) structure of that part of a folded peptide or protein recognized by its cognate biological receptor. This definition is closely related to the traditional view of an epitope, or "antigenic determinant", as being the part of an antigen recognized by antibodies and T-cell receptors (TCRs). The perspective here, however, is broader and includes not just structures recognized by antibodies and TCRs but also epitopes involved in ligand-receptor, protein-protein and protein-nucleic acid interactions (PPIs and PNIs). Most important are the 3D structures of epitopes and their mimicry in "semi-rigid" molecules. Protein epitope mimetics are interesting structurally and stereochemically, but more importantly, as tools to interrogate biological systems and as leads in drug and vaccine discovery.

Various levels of epitope complexity can be considered, starting with epitopes formed by short polypeptide segments at the protein surface, including $ß$-turns, loops and stretches of helical- or $\beta$-structure. $\beta$-Hairpins include both a turn (or loop) and regions of regular $\beta$ structure. Early successes in the design of ß-turn mimetics came in the 1980's and 1990's, whereas over the past decade several successful approaches to helical, $\beta$-sheet and $\beta$-hairpin mimetics have been described [1-5]. More complex is the mimicry of discontinuous epitopes, comprising multiple polypeptide chain segments lying adjacent on the protein surface and adopting multiple types of secondary structure; here remains an important challenge for the future [6], perhaps one that can be addressed through the evolving field of "foldamer chemistry" [7,8].

Protein epitope mimetics typically sit in a still relatively unexplored area of molecular space (ca. 0.5-5 kDa). Nature has evolved molecules in this size range, including many structurally complex polyketide and peptide-based natural products. On the other hand, an 
alternative source of such molecules is found by taking the macromolecules and macromolecular assemblies of Nature as a source of inspiration for mimetic design. Furthermore, many synthetic protein epitope mimetics tend to be modular in structure. They can be constructed from building blocks, such as $\alpha$ - or $\beta$-amino acids or peptoids, which can be linked together using robust and efficient methods. It then becomes straightforward, in principle, to exchange building blocks and so vary structures (and optimize properties) in a combinatorial fashion using parallel synthetic chemistry, something that is not so easy when starting from complex natural products.

Molecular recognition involving proteins is mediated by surface exposed secondary structure elements such as $\beta$-turns, $\beta$-strands, $\beta$-hairpins and $\alpha$-helices. Protein epitope mimetics, therefore, seem to be attractive starting points for the design of PPI (and PNI) inhibitors (Figure-1). Inhibitor design for such targets based on small drug-like molecules has often proven rather difficult [9]. Protein epitope mimetic design offers an alternative approach, which draws upon improving knowledge of the structures of PPI hot-spots and the mechanisms of PPIs [10]. Another area where protein epitope mimetics have great potential is in synthetic vaccine design. Here the epitope mimetic should indeed act as an antigenic determinant, not simply to mimic the structure and receptor binding properties of a specific target, but rather to stimulate the immune system to produce antibodies and/or cyotoxic $\mathrm{T}$ cells that recognize an invading pathogen.

In the remainder of this short review, the focus is on one application of protein epitope mimetics, for the discovery of novel anti-infective agents.

\section{Antibacterial CAMPs}

The WHO has identified antibiotic resistance as one of the greatest current threats to human health [11]. The reasons for this include the paucity of new antimicrobial drugs currently 
under development and the rapid spread of drug resistant bacteria [12]. In 2009 the Infectious Diseases Society of America (ISDA) challenged the USA and EU to develop ten new licensed antibiotics within the next 10 years, called the $10 x^{\prime} 20$ initiative (www.idsociety.org/10x20.htm) [13,14]. In order to address this challenge, it is important to consider new approaches to antibiotics that complement and extend established methods, such as natural product discovery and modification, whole-cell screening of compound libraries, and in vitro screens developed using genomic, proteomic and structural data [1517]. One alternative approach is the design of mimetics based upon the cationic peptide and protein effector molecules produced by cells in the innate immune system, which provide a first line of defense against microbial infection in birds, fishes, amphibians, reptiles, mammals (including humans), insects, and other organisms [18].

Cationic antimicrobial peptides (CAMPs), or so-called host-defense peptides, play important roles in the anti-infective defense mechanisms of many organisms, including those of animals that also possess a more complex adaptive immune system. They are typically short cationic peptides of $\sim 10-50$ residues, with a net positive charge of +2 to +10 , and often share amphipathic properties (cationic/hydrophobic). They differ widely, however, in sequences and secondary structures (Figure-2) (for recent reviews see [19-21]). Nevertheless, their physical properties frequently allow CAMPs to bind and insert into phosholipid bilayers by "barrel-stave", "carpet" or "toroidal-pore" mechanisms, and so disrupt the membrane bilayer [19]. CAMPs typically possess broad-spectrum antimicrobial activity against Gramnegative and Gram-positive microorganisms, but in the micromolar rather than the nanomolar range often seen with clinically used antibiotics. Nature has evolved CAMPs with such properties most likely because they are are released directly at sites of infection by effector cells, and then act locally in a number of ways, including by selective perturbation of microbial cytoplasmic membranes. In contrast, the relatively high concentrations of CAMPs 
needed for antimicrobial activity, their ready degradation by proteases in serum, and their higher toxicity, are major obstacles for their development and use in the systemic treatment of bacterial infections in humans.

The mechanisms of action of CAMPs, however, have additional layers of complexity. Firstly, the (outer) bacterial membranes are not simple bilayers containing phospholipids. The membranes of Gram-positive bacteria are typically covered in a thick layer of peptidoglycan, teichoic acid, and protein, whereas the outer membrane (OM) of Gram-negative bacteria are often asymmetric, with the outer leaflet comprising mostly lipopolysaccharide (LPS) [22]. Individual LPS molecules in the outer leaflet are then cemented together through coordination of the phosphate and carboxylate groups in lipid A to divalent cations such as $\mathrm{Mg}^{2+}$. It seems certain that cationic molecules (such as peptides and aminoglycosides) would be attracted electrostatically to the OM, perhaps leading to a pre-concentration in the outer sheaf [23]. This pre-association with the bacterial surface has been implicated in the selfpromoted uptake of peptides across the OM, perhaps through competion with $\mathrm{Mg}^{2+}$ for binding to LPS in Gram-negative bacteria like E. coli and P. aeruginosa [24]. But the molecular details of whether/how this might occur remain unclear. Certainly, many CAMPs act by disrupting microbial membranes, and in these cases both enantiomers tend to show the same antimicrobial activity, ostensibly due to a lack of chiral discrimination within the interior of the cell membrane. However, it is worth noting that some aminoglycosides remain active in both enantiomeric forms [25] although they target a chiral molecule - the ribosome [26]. Secondly, it is clear that in some cases CAMPs are able to penetrate the bacterial membrane(s), and gain access to protein or nucleic acid targets inside the cell, as reviewed elsewhere [27]. Thirdly, it should be remembered that many CAMPs also have broad functions in the immune systems of their hosts, in addition to their antimicrobial activity $[20,21]$. They act at the interface of the innate and adaptive immune responses, and 
participate in multiple aspects of immunity, inflammation, wound repair, and in maintaining homeostasis $[28,29]$. Recently, it was shown that some natural host-defence peptides, as well as synthetic analogues, can trigger a range of immunomodulatory responses, including an ability to moderate Toll-like receptor (TLR)-mediated responses stimulated by pathogenassociated molecular patterns and to protect against lethal endotoxemia and infections in animal models $[20,21,28,30,31]$. Other host-defence peptides such as the defensins and LL37 also have immunomodulatory activities that likely mediate protection in animal models. The detailed molecular mechanisms of these innate immune effects, however, remain poorly characterized.

These considerations suggest that CAMPs will be interesting starting points for peptidomimetic and foldamer design, with the aim of probing this biology and perhaps discovering molecules with interesting antimicrobial and/or immunomodulatory properties.

\section{CAMP mimetics}

\section{Antimicrobial peptides}

Many hundreds or thousands of linear synthetic peptides related to naturally occurring CAMPs have been reported that possess membrane lytic activity (e.g. [32-36]). However, it remains doubtful whether flexible linear peptides can be endowed with the properties, including high potency, target selectivity, low toxicity and stability in serum and in whole animals, required for drug development. On the other hand, these properties are easier to achieve with conformationally constrained peptidomimetic scaffolds. A lead can be taken from Nature, where many examples of backbone cyclic cationic peptide antimicrobial products are known [37]. For example, many analogues of natural products such as gramicidin $\mathrm{S}$ and tyrocidine have been reported, although their antimicrobial activities 
(MICs) usually remain in the micromolar range, and like the natural products, many are also strongly hemolytic.

\section{Antimicrobial peptidomimetics}

Many synthetic peptidomimetic approaches to antimicrobial peptides have been described or reviewed recently [38-40], including those based on hairpin mimetics [41-44], ß-peptides [45-54], peptoids [55-59], oligomeric aryl amides and aryl ureas [60-63], as well as related oligomers [64], foldamers and polymers (Figure-3) [65-73].

\section{Novel mechanisms of antimicrobial action}

Of special interest are cases where mixed and/or novel mechanisms of antimicrobial action can be demonstrated for CAMP-derived peptidomimetics. Already many years ago it was noted that individual CAMPs differ widely in their ability to depolarize the cytoplasmic membrane potential in Gram-positive and Gram-negative bacteria [24,74,75]. Gramicidin S, for example, causes maximal depolarization around the MIC, suggesting that the lytic actions of this peptide are directly responsible for bacterial cell death. Other CAMPs, however, such as polymyxin, cause little membrane depolarization at concentrations around the MIC, suggesting that the mechanism of cell death may involve some event other than the breakdown of the membrane permeability barrier. More recently, the kinetics of bacterial cell killing by antimicrobial arylamide foldamers was shown not to correlate with the effects of these molecules on bacterial membrane depolarization, suggesting again a mixed mechanism of action [61].

An interesting family of mimetics modelled on the $\beta$-hairpin structure of the CAMP protegrin I (PG-I) was shown recently to have a novel mechanism of action [44]. The mimetics, typified by L27-11 and POL7001, have a backbone cyclic structure constrained into a ß-hairpin conformation with a D-Pro-L-Pro template [1]. The discovery of L27-11 and POL7001 was enabled in particular by the availability of an efficient parallel synthesis 
method, which allowed the screening of compound libraries based upon this scaffold, and stepwise optimization of antimicrobial activity. Although PG-1 is strongly membrane lytic [76], both L27-11 and POL7001 are non-lytic at micromolar concentrations, and yet have potent antimicrobial activity in the nanomolar range, but only against Gram-negative Pseudomonas sp. The activity is highly enantioselective, which strongly suggests that a (chiral) receptor is required for the antimicrobial activity [44]. A likely target was shown to be the $\beta$-barrel OM protein LptD (also called OstA and Imp), which plays an essential role in the assembly of the LPS layer in the outer leaflet of the OM in many Gram-negative bacteria (Figure-4) [77,78]. The interaction of the peptidomimetics with $P$. aeruginosa LptD was proven by photoaffinity labelling [44], but the binding site has not yet been characterized in detail. LptD is known to form a complex with the lipoprotein LptE in the OM where together they are responsible for the transport of LPS from the periplasm into the outer leaflet of the OM $[77,79,80]$. No crystal structure of LptD (from any microorganism) is currently available. It is also unclear how LptD interacts with LptE and how LPS transport to the outer leaflet occurs. The results available so far support the hypothesis that the antimicrobial activity of the $\beta$-hairpin mimetics is due to inhibition of the key transport function of $L p t D$, which then blocks OM biogenesis. More detailed studies are now required to investigate the influence the mimetics have on LPS transport to the OM.

\section{Other CAMPs that target OM proteins}

Some naturally occurring antimicrobial peptides and proteins are known to interact with $\beta$ barrel OM proteins in Gram-negative bacteria, in particular, the colicins and closely related bacteriocins and microcins [81]. Many of these peptides and proteins have been shown to hijack B-barrel proteins, including porins $(\mathrm{OmpA} / \mathrm{C} / \mathrm{F})$ and those used to transport vitamin $\mathrm{B}_{12}$ and iron across the $\mathrm{OM}$, to gain access to the periplasm. Recently, an intrinsically unstructured region close to the N-terminus of bacteriocin ColE9a was observed in a crystal 
structure inside the OmpF ß-barrel.[82] The killing mechanisms of these antibiotics, however, are unrelated to the mechanism of transport across the OM, and typically involve protein or nucleic acid targets in the cytoplasm [81]. On the other hand, no natural products (including peptides or proteins) have so far been reported that interact with LptD or related essential OM proteins, such as BamA/Omp85/YaeT [83]. This is all the more surprising given their essential functions in OM biogenesis, and their exposed position in the OM.

\section{Peptidomimetics targeting CXCR4}

Polyphemusin is a naturally occurring ß-hairpin CAMP (Figure-2) with antiviral activity against HIV-1 due to its ability to antagonize the chemokine receptor CXCR4; the major coreceptor used by T-cell-tropic (X4-) HIV-1 to invade T-lymphocytes. CXCR4 is a G-protein coupled receptor that binds a protein ligand called "stromal cell-derived factor-1" (SDF-1 or CXCL12). Polyphemusin has been used as a starting point for the discovery of potentially useful CXCR4 antagonists [84-88]. One example is a family of backbone cyclic ß-hairpin mimetics, which again exploit the D-Pro-L-Pro template and a disulfide cross-link to stabilize hairpin conformations. Recently, an X-ray crystal structure revealed how one hairpin peptide binds to an engineered form of CXCR4 (Figure-4) [89]. The $\beta$-hairpin inserts deep into the SDF-1 binding pocket, where a network of polar, hydrogen-bonding and hydrophobic contacts between the ligand and the receptor are responsible for the specific high affinity interaction. The ligand-binding site on $\mathrm{CXCR} 4$ is formed by residues in the inward-facing, protruding walls of the seven transmembrane helical bundle, several extracellular loops, and the N-terminal segment. It will be interesting to discover whether other GPCRs, that also have protein ligands, possess binding sites with similar architecture. If so, the structures and properties of the $\beta$-hairpin scaffold might be readily optimized for interacting with such sites.

\section{Acknowledgements}


Special thanks to Kerstin Moehle for preparing the graphics.

\section{References and recommended reading}

Papers of particular interest, published within the period of review, have been highlighted as:

- of special interest

-0 of outstanding interest

1. Robinson JA: B-Hairpin peptidomimetics: design, structures and biological activities. Accts. Chem. Res. 2008, 41:1278-1288.

2. Ross NT, Katt WP, Hamilton AD: Synthetic mimetics or protein secondary structure domains. Phil. Trans. R. Soc. A 2010, 368:989-1008.

3. Henchey LK, Jochim AL, Arora PS: Contemporary strategies for the stabilization of peptides in the $\alpha$-helical conformation. Curr. Opin. Chem. Biol. 2008, 12:692697.

4. Graner J, Harding MM: Design and synthesis of $\boldsymbol{\alpha}$-helical peptides and mimetics. Org. Biomol. Chem. 2007, 5:3577-3585.

5. Nowick JS: Exploring B-Sheet Structure and Interactions with Chemical Model Systems. Accts Chem. Res. 2008, 41:1319-1330.

6. Eichler J: Peptides as protein binding site mimetics. Curr. Opin. Chem. Biol. 2008, 12:707-713.

7. Goodman CM, Choi S, Shandler S, DeGrado WF: Foldamers as versatile frameworks for the design and evolution of function. Nat. Chem. Biol. 2007, 3:252-262.

8. Horne WS, Gellman SH: Foldamers with heterogeneous backbones. Accts. Chem. Res. 2008, 41:1399-1408.

9. Wells JA, McClendon CL: Reaching for high-hanging fruit in drug discovery at protein-protein interfaces. Nature 2007, 450:1001-1009.

10. Reichmann D, Rahat O, Cohen M, Neuvirth H, Schreiber G: The molecular architecture of protein-protein binding sites. Curr. Opin. Struct. Biol. 2007, 17:6776.

11. Editorial: Urgently needed: new antibiotics. The Lancet 2009, 374:1868-1868.

12. Taubes G: The bacteria fight back. Science 2008, 321:356-361.

13. Boucher HW, Talbot GH, Bradley JS, Edwards JE, Gilbert D, Rice LB, Scheld M, Spellberg B, Bartlett J: Bad Bugs, No Drugs: No ESKAPE! An Update from the Infectious Diseases Society of America. Clin. Infect. Diseases 2009, 48:1-12.

14. Gilbert DN, Guidos RJ, Boucher HW, Talbot GH, Spellberg B, Edwards JE, Scheld WM, Bradley JS, Bartlett JG: The 10x'20 Initiative: Pursuing a Global Commitment to Develop 10 New Antibacterial Drugs by 2020. Clin. Infect. Diseases 2010, 50:1081-1083.

15. Payne DJ, Gwynn MN, Holmes DJ, Pompliano DL: Drugs for bad bugs: confronting the challenges of antibacterial discovery. Nat. Rev. Drug Discov. 2007, 6:29-40.

16. Bumann D: Has nature already identified all useful antibacterial targets. Curr. Opin. Microbiol. 2008, 11:387. 
17. Falconer SB, Brown ED: New screens and targets in antibacterial drug discovery. Curr. Opin. Microbiol. 2009, 12:497-504.

18. Hancock REW, Sahl H-G: Antimicrobial and host-defense peptides as new antiinfective therapeutic strategies. Nat. Biotech. 2006, 24:1551-1557.

19. Brogden KA: Antimicrobial peptides: Pore formers or metabolic inhibitors in bacteria? Nat. Rev. Microbiol. 2005, 3:238-250.

20. Lai Y, Gallo RL: AMPed up immunity: how antimicobial peptides have multiple roles in immune defense. Trends Immunol. 2009, 30:131-141.

21. Brown KL, Hancock REW: Cationic host defense (antimicrobial) peptides. Curr. Opin. Immunol. 2006, 18:24-30.

22. Silhavy TJ, Kahne D, Walker S: The Bacterial Cell Envelope. Cold Spring Harb. Perspect. Biol. 2010, 2:16.

23. Melo MN, Ferre R, Castanho MARB: Antimicrobial peptides: linking partition, activity and high membrane-bound concentrations. Nat. Rev. Microbiol. 2009, 7:245-250.

24. Wu M, Maier E, Benz R, Hancock REW: Mechanism of Interaction of Different Classes of Cationic Antimicrobial Peptides with Planar Bilayers and with the Cytoplasmic Membrane of Escherichia coli. Biochemistry 1999, 38:7235-7242.

25. Ryu DH, Litovchick A, Rando RR: Stereospecificity of aminoglycoside-ribosomal interactions. Biochemistry 2002, 41:10499-10509.

26. Silva JG, Carvalho I: New insights into aminoglycoside antibiotics and derivatives. Curr. Med. Chem. 2007, 14:1101.

27. Nicolas P: Multifunctional host defense peptides: intracellular-targeting antimicrobial peptides. FEBS J. 2009, 276:6483-6496.

28. Auvynet C, Rosenstein Y: Multifunctional host defense peptides: Antimicrobial peptides, the small yet big players in innate and adaptive immunity. FEBS $J$. 2009, 276:6497-6508.

29. Strominger JL: Animal Antimicrobial Peptides: Ancient Players in Innate Immunity. J. Immunol. 2009, 182:6633-6634.

30. Wieczorek M, Jenssen H, Kindrachuk J, Scott WRP, Elliott M, Hilpert K, Cheng JTJ, Hancock REW, Straus SK: Structural Studies of a Peptide with Immune Modulating and Direct Antimicrobial Activity. Chem. Biol. 2010, 17:970-980.

- A synthetic innate defense regulator peptide that potently induces chemokine responses, suppresses TNF $\alpha$ responses, and kills bacteria.

31. Scott MG, Dullaghan E, Mookherjee N, Glavas N, Waldbrook M, Thompson A, Wang A, Lee K, Doria S, Hamill P, et al.: An anti-infective peptide that selectively modulates the innate immune response. Nat. Biotech. 2007, 25:465-472.

- A small synthetic cationic peptide provides significant protection against infection with $S$. aureus in an animal model, and yet shows no direct antimicrobial activity in a typical microplate assay (MIC $>128 \mu \mathrm{g} / \mathrm{ml}$ ). The peptide was shown to act through MAP kinase and other signalling pathways to enhance the levels of monocyte chemokines while reducing pro-inflammatory cytokine responses.

32. Giuliani A, Pirri G, Nicoletto S: Antimicrobial peptides: an overview of a promising class of therapeutics. Central Eur. J. Biol. 2007, 2:1-33.

33. Cherkasov A, Hilpert K, Jenssen H, Fjell CD, Waldbrook M, Mullaly SC, Volkmer R, Hancock REW: Use of Artificial Intelligence in the Design of Small Peptide 
Antibiotics Effective against a Broad Spectrum of Highly Antibiotic-Resistant Superbugs. ACS Chem. Biol. 2009, 4:65-74.

- A machine-learning approach to the discovery of novel linear cationic antimicrobial peptides. Experimental data from large random peptide libraries is taken in combination with the descriptive power of atomic-resolution chemical descriptors and the predictive ability of an artificial neural net approach.

34. Easton DM, Nijnik A, Mayer ML, Hancock REW: Potential of immunomodulatory host defense peptides as novel anti-infectives. Trends Biotechnol. 2009, 27:582590.

35. Fjell CD, Jenssen H, Hilpert K, Cheung WA, Pante N, Hancock REW, Cherkasov A: Identification of Novel Antibacterial Peptides by Chemoinformatics and Machine Learning. J. Med. Chem. 2009, 52:2006-2015.

36. Hilpert K, Elliott M, Jenssen H, Kindrachuk J, Fjell CD, Korner J, Winkler DFH, Weaver LL, Henklein P, Ulrich AS, et al.: Screening and Characterization of Surface-Tethered Cationic Peptides for Antimicrobial Activity. Chem. Biol. 2009, 16:58-69.

37. Nolan EM, Walsh CT: How nature morphs peptide scaffolds into antibiotics. ChemBioChem 2009, 10:34-53.

38. Vaara M: New approaches in peptide antibiotics. Curr. Opin. Pharmacol. 2009, 9:571-576.

39. Giuliani A, Pirri G, Bozzi A, Di Giulio A, Aschi M, Rinaldi AC: Antimicrobial peptides: natural templates for synthetic membrane-active compounds. Cell Mol. Life Sci. 2008, 65:2450-2460.

40. Vooturi SK, Firestine SM: Synthetic Membrane-Targeted Antibiotics. Curr. Med. Chem. 2010, 17:2292-2300.

41. Robinson JA, Shankaramma SC, Jettera P, Kienzl U, Schwendener RA, Vrijbloed JW, Obrecht D: Properties and structure-activity studies of cyclic beta-hairpin peptidomimetics based on the cationic antimicrobial peptide protegrin I. Bioorg. Med. Chem. 2005, 13:2055-2064.

42. Shankaramma SC, Athanassiou Z, Zerbe O, Moehle K, Mouton C, Bernardini F, Wrijbloed JW, Obrecht D, Robinson JA: Macrocyclic hairpin mimetics of the cationic antimicrobial peptide protegrin I: A new family of broad-spectrum antibiotics. ChemBioChem. 2002, 3:1126-1133.

43. Shankaramma SC, Moehle K, James S, Vrijbloed JW, Obrecht D, Robinson JA: A family of macrocyclic antibiotics with a mixed peptide-peptoid B-hairpin backbone conformation. Chem. Comm. 2003:1842-1843.

44. Srinivas N, Jetter P, Ueberbacher BJ, Werneburg M, Zerbe K, Steinmann J, Van der Meijden B, Bernardini F, Lederer A, Dias RLA, et al.: Peptidomimetic Antibiotics Target Outer-Membrane Biogenesis in Pseudomonas aeruginosa. Science 2010, 327:1010-1013.

- The first report of $\beta$-hairpin mimetic peptides that target the OM protein LptD in $P$. aeruginosa, and likely have a novel mechanism of action.

45. Arvidsson PI, Ryder NS, Weiss HM, Gross G, Kretz O, Woessner R, Seebach D: Antibiotic and Hemolytic Activity of a $\beta 2 / \beta 3$ Peptide Capable of Folding into a 12/10-Helical Secondary Structure. ChemBioChem 2003, 4:1345-1347. 
46. Epand RF, Raguse L, Gellman SH, Epand RM: Antimicrobial 14-Helical BPeptides: Potent Bilayer Disrupting Agents. Biochemistry 2004, 43:9527-9535.

47. Hamuro Y, Schneider JP, DeGrado WF: De novo design of antibacterial B-peptides. J. Am. Chem. Soc. 1999, 121:12200-12201.

48. Liu D, DeGrado WF: De Novo Design, Synthesis, and Characterization of Antimicrobial B-Peptides. J. Am. Chem. Soc. 2001, 123:7553-7559.

49. Porter EA, Wang X, Lee H-S, Weisblum B, Gellman SH: Non-haemolytic B-aminoacid oligomers. Nature 2000, 404:565.

50. Porter EA, Weisblum B, Gellman SH: Mimicry of Host-Defense Peptides by Unnatural Oligomers: Antimicrobial B-Peptides. J. Am. Chem. Soc. 2002, 124:7324-7330.

51. Porter EA, Weisblum B, Gellman SH: Use of Parallel Synthesis To Probe Structure-Activity Relationships among 12-Helical B-Peptides: Evidence of a Limit on Antimicrobial Activity. J. Am. Chem. Soc. 2005, 127:11516-11529.

52. Raguse TL, Porter EA, Weisblum B, Gellman SH: Structure-Activity Studies of 14Helical Antimicrobial B-Peptides: Probing the Relationship between Conformational Stability and Antimicrobial Potency. J. Am. Chem. Soc. 2002, 124:12774-12785.

53. Schmitt MA, Weisblum B, Gellman SH: Unexpected Relationships between Structure and Function in $\alpha, \beta$-Peptides: Antimicrobial Foldamers with Heterogeneous Backbones. J. Am. Chem. Soc. 2004, 126:6848-6849.

54. Schmitt MA, Weisblum B, Gellman SH: Interplay among Folding, Sequence, and Lipophilicity in the Antibacterial and Hemolytic Activities of $\alpha / \beta$-Peptides. $J$. Am. Chem. Soc. 2006, 129:417-428.

55. $\mathrm{Ng} \mathrm{S}$, Goodson B, Ehrhardt A, Moos WH, Siani M, Winter J: Combinatorial discovery process yields antimicrobial peptoids. Bioorg. Med. Chem. 1999, 7:17811785.

56. Patch JA, Barron AE: Helical peptoid mimics of magainin-2 amide. J. Am. Chem. Soc. 2003, 125:12092-12093.

57. Chongsiriwatana NP, Patch JA, Czyzewski AM, Dohm MT, Ivankin A, Gidalevitz D, Zuckermann RN, Barron AE: Peptoids that mimic the structure, function, and mechanism of helical antimicrobial peptides. Proc. Nat. Acad. Sci. USA 2008, 105:2794-2799.

- The design of ampetoids; antimicrobial peptoid oligomers with helical structures and biomimetic sequences, several members of which have low-micromolar antimicrobial activities.

58. Olsen CA, Ziegler HL, Nielsen HM, Frimodt-Møller N, Jaroszewski JW, Franzyk H: Antimicrobial, Hemolytic, and Cytotoxic Activities of $\beta$-Peptoid-Peptide Hybrid Oligomers: Improved Properties Compared to Natural AMPs. ChemBioChem 2010, 11:1356-1360.

59. Gobbo M, Benincasa M, Bertoloni G, Biondi B, Dosselli R, Papini E, Reddi E, Rocchi R, Tavano R, Gennaro R: Substitution of the Arginine/Leucine Residues in Apidaecin Ib with Peptoid Residues: Effect on Antimicrobial Activity, Cellular Uptake, and Proteolytic Degradation. J. Med. Chem. 2009, 52:5197-5206.

60. Scott RW, DeGrado WF, Tew GN: De novo designed synthetic mimics of antimicrobial peptides. Curr. Opin. Biotech. 2008, 19:620-627. 
61. Choi S, Isaacs A, Clements D, Liu DH, Kim H, Scott RW, Winkler JD, DeGrado WF: De novo design and in vivo activity of conformationally restrained antimicrobial arylamide foldamers. Proc. Nat. Acad. Sci. USA 2009, 106:6968-6973.

- Small (molecular mass $<1,000 \mathrm{Da}$ ) arylamide foldamers that mimic antimicrobial peptides. Hydrogen-bonded restraints in the arylamide template rigidify the conformation via hydrogen bond formation and increase activity toward Staphylococcus aureus and Escherichia coli. The designed foldamers are highly active against $S$. aureus in an animal model.

62. Gabriel GJ, Tew GN: Conformationally rigid proteomimetics: a case study in designing antimicrobial aryl oligomers. Org. Biomol. Chem. 2008, 6:417-423.

63. Liu DH, D., Choi S, Chen B, Doerksen RJ, Clements DJ, Winkler JD, Klein ML, DeGrado WF: Nontoxic membrane-active antimicrobial arylamide oligomers. Angew. Chem. Int. Ed. 2004, 43:1158-1162.

64. Radzishevsky IS, Rotem S, Bourdetsky D, NavonVenezia S, Carmeli Y, Mor A: Improved antimicrobial peptides based on acyl-lysine oligomers. Nat. Biotechnol. 2007, 25:657-659.

Forget the conformational restraints - peptidomimetic oligomers that show rapid, nonhemolytic, broad-spectrum bactericidal properties in mice and do not induce the emergence of resistance. The oligomers contain acyl chains, which prevent the formation of stable secondary structure.

65. Kuroda K, DeGrado WF: Amphiphilic polymethacrylate derivatives as antimicrobial agents. J. Am. Chem. Soc. 2005, 127:4128-4129.

66. Tew GN, Scott RW, Klein ML, DeGrado WF: De Novo Design of Antimicrobial Polymers, Foldamers, and Small Molecules: From Discovery to Practical Applications. Accts. Chem. Res. 2010, 43:30-39.

- Describes efforts to design and synthesize "foldamers" - short sequence-specific oligomers based on arylamide and $\beta$-amino acid backbones, which fold into well-defined secondary structures - that could act as antimicrobial agents.

67. Mowery BP, Lee SE, Kissounko DA, Epand RF, Epand RM, Weisblum B, Stahl SS, Gellman SH: Mimicry of Antimicrobial Host-Defense Peptides by Random Copolymers. J. Am. Chem. Soc. 2007, 129:15474-15476.

68. Claudon P, Violette A, Lamour K, Decossas M, Fournel S, Heurtault B, Godet J, Mély Y, Jamart-Grégoire B, Averlant-Petit $\mathrm{M}-\mathrm{C}$, et al.: Consequences of Isostructural Main-Chain Modifications for the Design of Antimicrobial Foldamers: Helical Mimics of Host-Defense Peptides Based on a Heterogeneous Amide/Urea Backbone. Angew. Chem. Int. Ed. 2010, 49:333-336.

- Oligoureas and $\gamma$-peptides are isosteric, quasi-isostructural helical foldamers endowed with distinct biomolecular recognition properties. Combination of the two backbones to generate urea/amide hybrids was found to give more potent yet less cytotoxic antimicrobial helical foldamers. 
69. Gabriel GJ, Madkour AE, Dabkowski JM, Nelson CF, Nusslein K, Tew GN: Synthetic Mimic of Antimicrobial Peptide with Nonmembrane-Disrupting Antibacterial Properties. Biomacromolecules 2008, 9:2980-2983.

70. Lienkamp K, Tew GN: Synthetic Mimics of Antimicrobial Peptides-A Versatile Ring-Opening Metathesis Polymerization Based Platform for the Synthesis of Selective Antibacterial and Cell-Penetrating Polymers. Chem. Eur. J. 2009, 15:11784-11800.

71. Tew GN, Liu D, Chen B, Doerksen RJ, Kaplan J, Carroll PJ, Klein ML, DeGrado WF: De novo design of biomimetic antimicrobial polymers. Proc. Nat. Acad. Sci. USA 2002, 99:5110-5114.

72. Bremner JB, Keller PA, Pyne SG, Boyle TP, Brkic Z, David DM, Garas A, Morgan J, Robertson M, Somphol K, et al.: Binaphthyl-Based Dicationic Peptoids with Therapeutic Potential. Angew. Chem. Int. Ed. 2010, 49:537-540.

73. Bremner JB, Keller PA, Pyne SG, Boyle TP, Brkic Z, Morgan J, Somphol K, Coates JA, Deadman J, Rhodes DI: Synthesis and antibacterial studies of binaphthylbased tripeptoids. Part 2. Bioorg. Med. Chem. 2010, 18:4793-4800.

74. Friedrich CL, Moyles D, Beveridge TJ, Hancock REW: Antibacterial Action of Structurally Diverse Cationic Peptides on Gram-Positive Bacteria. Antimicrob. Agents Chemother. 2000, 44:2086-2092.

75. Zhang L, Dhillon P, Yan H, Farmer S, Hancock REW: Interactions of Bacterial Cationic Peptide Antibiotics with Outer and Cytoplasmic Membranes of Pseudomonas aeruginosa. Antimicrob. Agents Chemother. 2000, 44:3317-3321.

76. Bolintineanu D, Hazrati E, Davis HT, Lehrer RI, Kaznessis YN: Antimicrobial mechanism of pore-forming protegrin peptides: 100 pores to kill E. coli. Peptides 2010, 31:1-8.

77. Ruiz N, Kahne D, Silhavy TJ: Transport of lipopolysaccharide across the cell envelope: the long road of discovery. Nat. Revs. Microbiol. 2009, 7:677-683.

78. Sperandeo P, Dehó G, Polissi A: The lipopolysaccharide transport system of Gram-negative bacteria. Biochim. Biophys. Acta 2009, 1791:594-602.

79. Chng S-S, Ruiz N, Chimalakonda G, Silhavy TJ, Kahne D: Characterization of the two-protein complex in Escherichia coli responsible for lipopolysaccharide assembly at the outer membrane. Proc. Natl. Acad. Sci. USA 2010, 107:5363-5368.

- The biochemical characterization of the two-protein complex consisting of LptD and LptE that is responsible for the assembly of LPS at the cell surface.

80. Chng SS, Gronenberg LS, Kahne D: Proteins Required for Lipopolysaccharide Assembly in Escherichia coli Form a Transenvelope Complex. Biochemistry 2010, 49:4565-4567.

81. Cascales E, Buchanan SK, Duche D, Kleanthous C, Lloubes R, Postle K, Riley M, Slatin S, Cavard D: Colicin Biology. Microbiol. Mol. Biol. Revs. 2007, 71:158-229.

82. Housden NG, Wojdyla JA, Korczynska J, Grishkovskaya I, Kirkpatrick N, Brzozowski AM, Kleanthous C: Directed epitope delivery across the Escherichia coli outer membrane through the porin OmpF. Proc. Nat. Acad. Sci. USA 2010, 107:21412-21417.

- Elucidates the mechanism by which an entire soluble protein domain of bacteriocin ColE9 $(>6 \mathrm{kDa})$ is delivered through the lumen of $\mathrm{OmpF}$ and $\mathrm{OmpC}$; including the structure of a OmpF-peptide complex that shows the colicin bound within the porin lumen spanning the membrane bilayer. The study explains how a flexible peptide with narrow cross-sectional 
area has the ability to traverse a biological membrane via the constricted lumen of a $\beta$-barrel membrane protein.

83. Walther DM, Rapaport D, Tommassen $\mathrm{J}$ : Biogenesis of B-barrel membrane proteins in bacteria and eukaryotes: evolutionary conservation and divergence. Cell. Mol. Life Sci. 2009, 66:2789-2804.

84. DeMarco SJ, Henze H, Lederer A, Moehle K, Mukherjee R, Romagnoli B, Robinson JA, Brianza F, Gombert FO, Lociuro S, et al.: Discovery of novel, highly potent and selective beta-hairpin mimetic CXCR4 inhibitors with excellent anti-HIV activity and pharmacokinetic profiles. Bioorgan. Med. Chem. 2006, 14:8396-8404.

85. Moncunill G, Armand-Ugón M, Clotet-Codina I, Pauls E, Ballana E, Llano A, Romagnoli B, Vrijbloed JW, Gombert FO, Clotet B, et al.: Anti-HIV Activity and Resistance Profile of the CXC Chemokine Receptor 4 Antagonist POL3026. Mol. Pharmacol. 2008, 73:1264-1273.

86. Tamamura H, Tsutsumi H, Masuno H, Fujii N: Development of low molecular weight CXCR4 antagonists by exploratory structural tuning of cyclic tetra- and pentapeptide-scaffolds towards the treatment of HIV infection, cancer metastasis and rheumatoid arthritis. Curr. Med. Chem. 2007, 14:93-102.

87. Ueda S, Oishi S, Wang ZX, Araki T, Tamamura H, Cluzeau J, Ohno H, Kusano S, Nakashima H, Trent JO, et al.: Structure-activity relationships of cyclic peptidebased chemokine receptor CXCR4 antagonists: Disclosing the importance of side-chain and backbone functionalities. J. Med. Chem. 2007, 50:192-198.

88. Tamamura H, Araki T, Ueda S, Wang ZX, Oishi S, Esaka A, Trent JO, Nakashima H, Yamamoto N, Peiper SC, et al.: Identification of novel low molecular weight CXCR4 antagonists by structural tuning of cyclic tetrapeptide scaffolds. $J$. Med. Chem. 2005, 48:3280-3289.

89. Wu BL, Chien EYT, Mol CD, Fenalti G, Liu W, Katritch V, Abagyan R, Brooun A, Wells P, Bi FC, et al.: Structures of the CXCR4 Chemokine GPCR with SmallMolecule and Cyclic Peptide Antagonists. Science 2010, 330:1066-1071.

-0 The G protein-coupled chemokine receptor CXCR4 is specifically implicated in cancer metastasis and HIV-1 infection. A crystal structure of CXCR4 bound to a cyclic peptide provides structural insights into how a G-protein-coupled receptor recognizes a $ß$-hairpin mimetic based on the CAMP polyphemusin.

90. Pettersen EF, Goddard TD, Huang CC, Couch GS, Greenblatt DM, Meng EC, Ferrin TE: UCSF chimera - A visualization system for exploratory research and analysis. J. Comp. Chem. 2004, 25:1605-1612. 
Figure-1. The starting points for protein epitope mimetic design are the products of structural and molecular biology (for example, left, the CD4-gp120-mAb crystal structure (PDB 2QAD); right, the human papillomavirus-like particle L1 capsid (PDB 1DZL)). Some potential areas of application of protein epitope mimetics are highlighted.

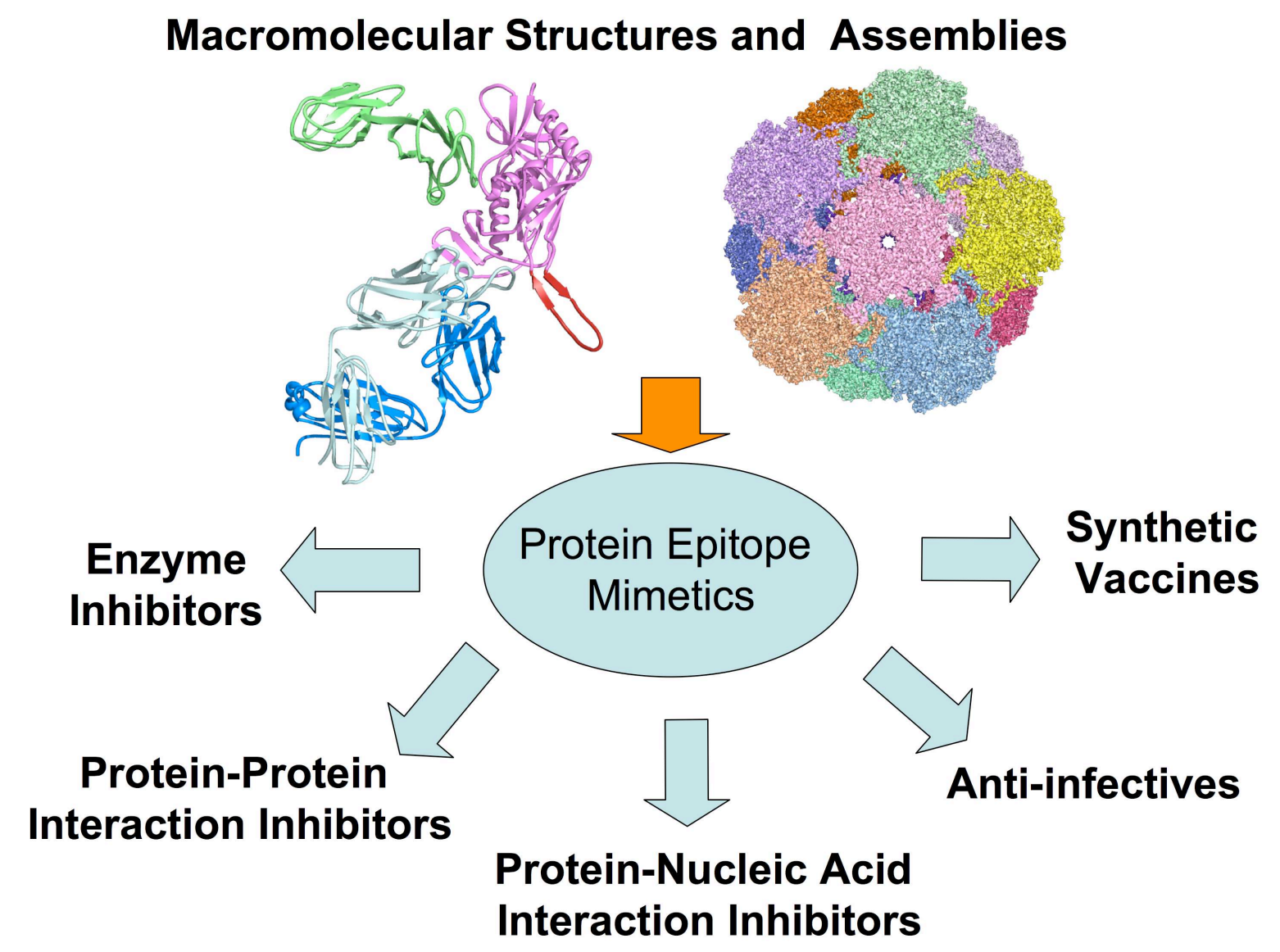


Figure-2. Cationic antimicrobial peptides come in a variety of shapes and sizes. A selection of structures is shown, with the name and PDB file.

1FD3: human ß-defensin 2

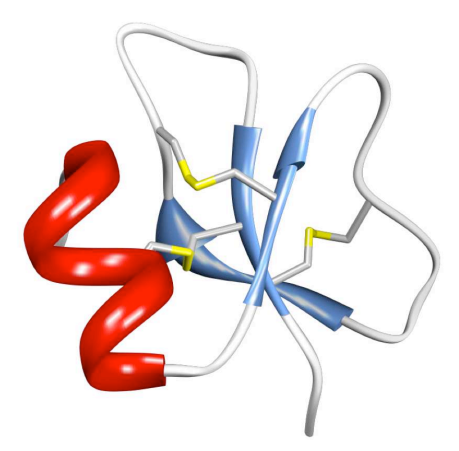

1G89: indolicidin

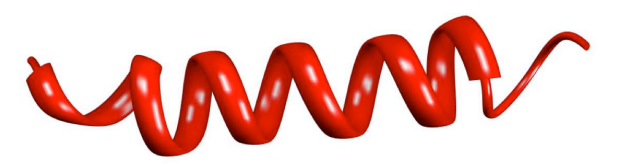

1Z64: pleurocidin

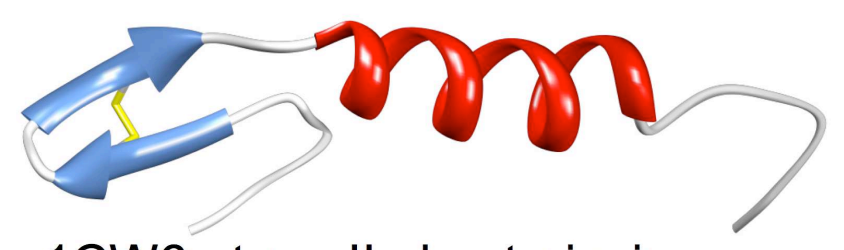

1CW6: type-Ila bacteriocin
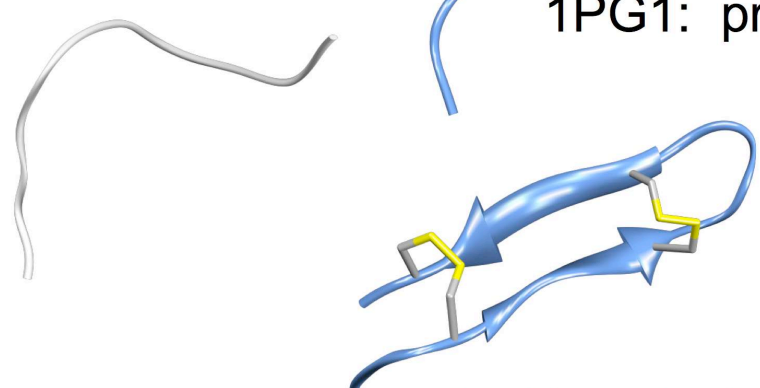

2B5K: polyphemusin I

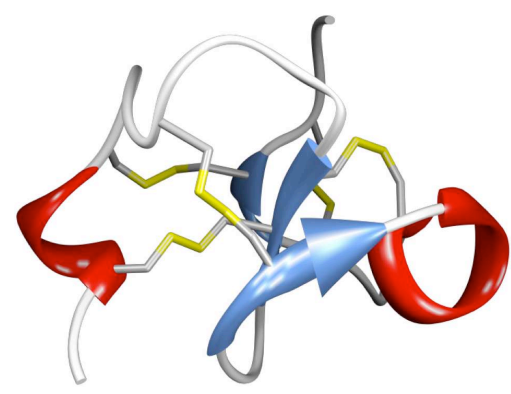

1P9Z: antifungal peptide 
Figure-3. A selection of CAMP mimetics based on; A, oligomers and related; B, peptoids; $\mathbf{C}$, B-peptides.

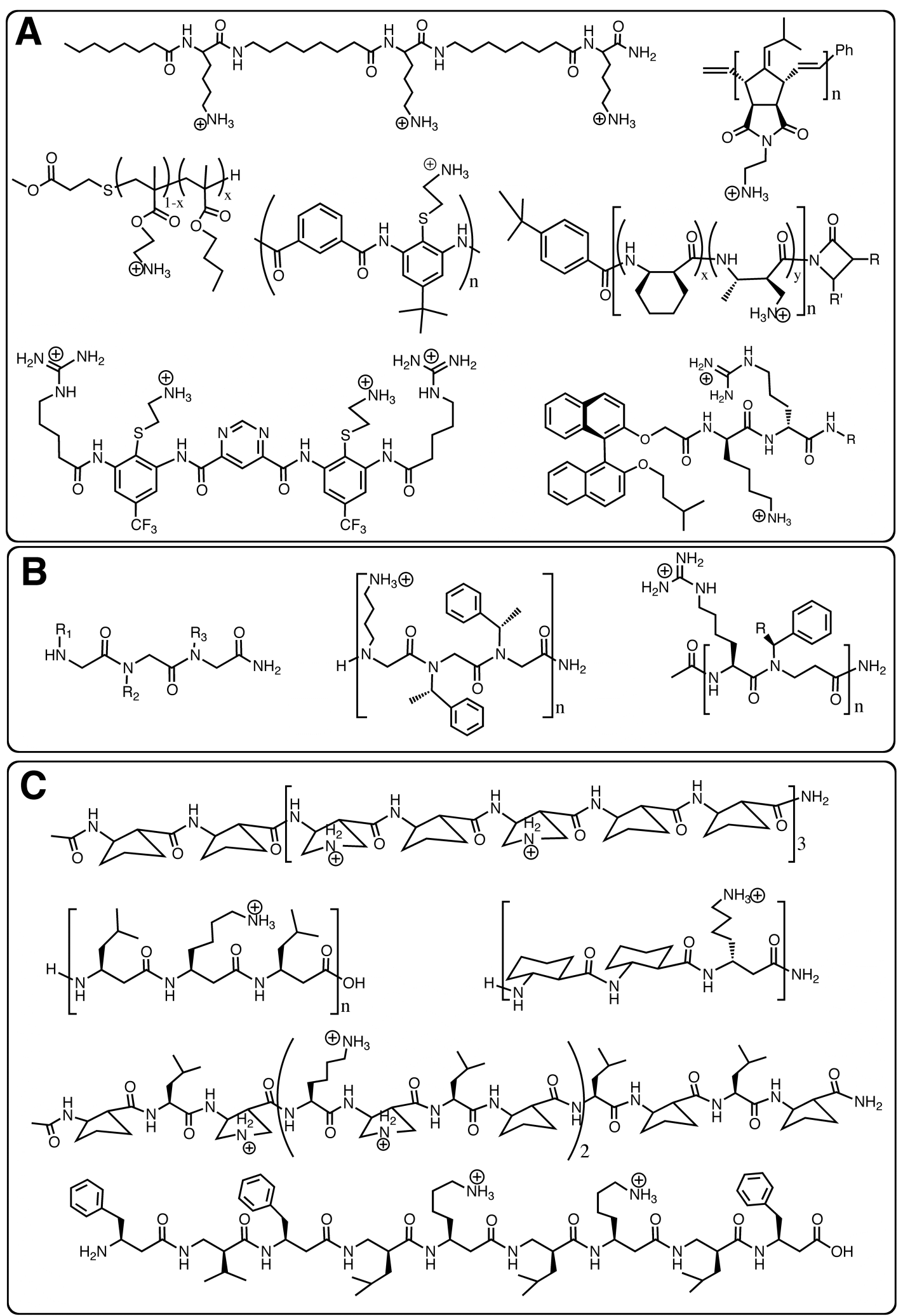


Figure-4. ß-Hairpin mimetics derived from protegrin I and polyphemusin (Figure-2) bind, respectively, to the bacterial outer membrane protein LptD [44] and the chemokine receptor CXCR4 [84]; left, LptD (red) is an OM protein, comprising a C-terminal $\beta$-barrel (the $ß$ barrel shown is from PDB 2VQI) and an N-terminal periplasmic domain. LptD forms a complex with the lipoprotein LptE (green) $[77,79,80]$. The structure for LptE shown is that in PDB 2JXP (see text); right, the crystal structure of a ß-hairpin peptide (green with red surface) bound to the G-protein coupled receptor CXCR4 (PDB 3oe0) [89]. A slice through the complex is shown in a blue surface representation, with the full ribbon structure of CXCR4 in white. The image was made using the UCSF program Chimera [90].

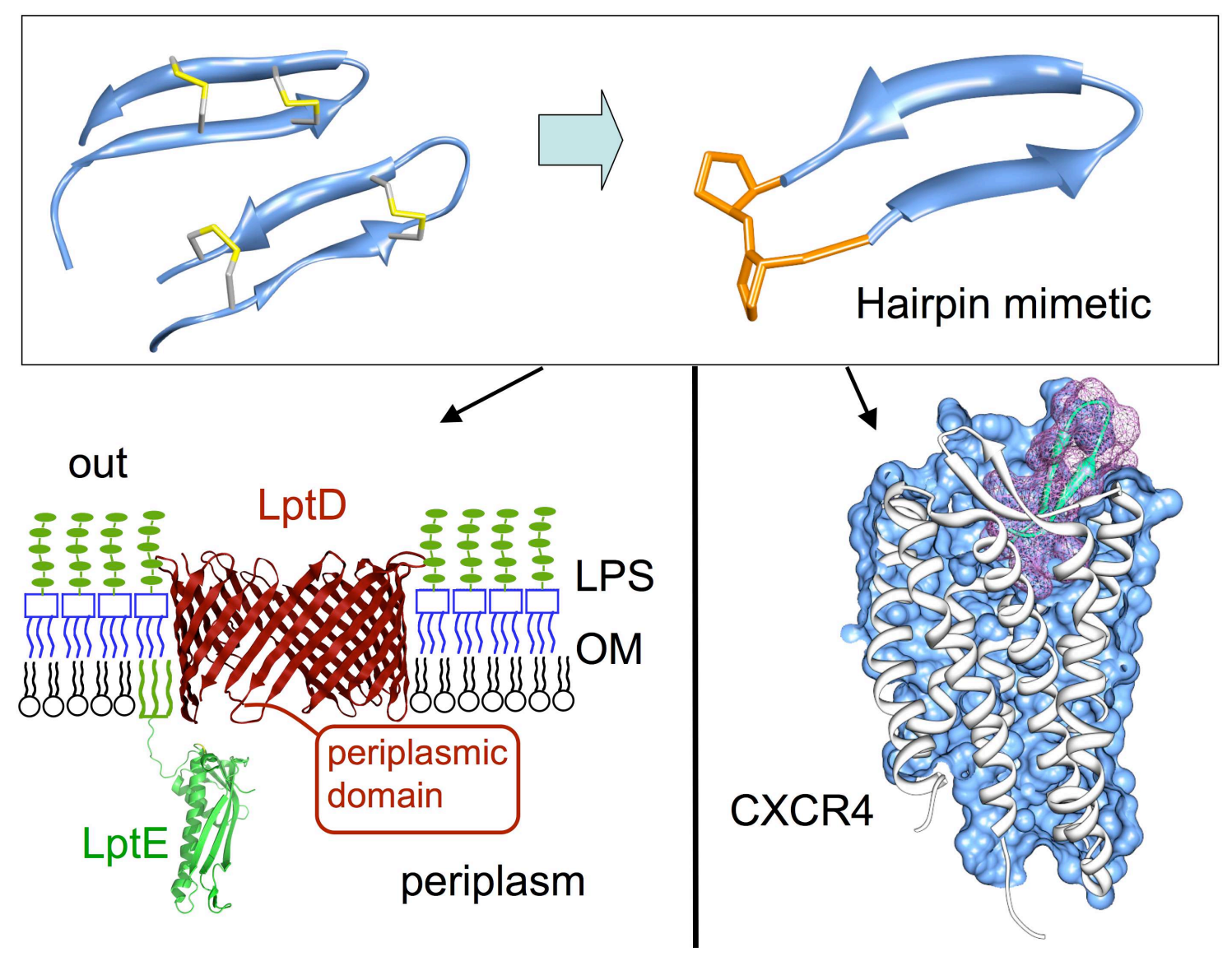

